\title{
A STUDY ON THE DRY UNI-DIRECTIONAL SLIDING BEHAVIOUR OF TITANIUM ALUMINIDES
}

\author{
C.L. Chu and S.K. Wu \\ Institute of Materials Science and Engincering, National Taiwan University \\ Taipei, Taiwan 106, Republic of China \\ (Received November 28, 1994) \\ (Revised February 23, 1995)
}

\section{Introduction}

Titanium aluminides are potential structural materials for use at elevated temperatures. They have low density, high specific strength and high melting points. However, their inherently low ductility and workability at room temperature restrict their applications in critical applications [1]. At the same time, their low surface hardness may restrict their tribological applications. Several investigations of wear resistance have been done on titanium and surface modified titanium alloys [2-4]. However, to our best knowledge, there is little data on the tribological characteristics of titanium aluminides [5]. In this study, employing various sliding speeds and applied loads, the effects of aluminum content on the wear resistance of titanium aluminides in a dry uni-directional sliding wear test are investigated. Their tribological characteristics of titanium aluminides are also discussed.

\section{Experimental Procedure}

A conventional tungsten arc melting technique was employed to prepare four titanium aluminides containing 25, 40, 50 and 53 at.\%Al, respectively. Titanium (purity, 99.7\%) and aluminum (purity, 99.99\%) totaling $100 \mathrm{~g}$, were melted and remelted at least six times in a low pressure argon atmosphere. Pure titanium buttons were also melted and used as getters. The mass loss during melting was negligable. The as-melted buttons were homogenized at $1050^{\circ} \mathrm{C}$ in a $7 \times 10^{-6}$ torr vacuum furance for 4 days. Specimens with dimensions of $12.5 \times 12.5 \times 1 \mathrm{~mm}$ were then cut from the homogenized buttons using a low-speed diamond saw. The specimen surfaces were then polished with 1000 grit emery paper. Before wear testing, all specimens were cleaned ultra-sonically in acetone to remove surface grease, and the surface roughness and the surface apparent hardness were measured. These values are listed in Table 1.

The friction tests were performed using a uni-directional sliding testing machine, model TE53 manufactured by Plint \& Partners Ltd., England, and shown schematically in Fig. 1. In this machine, there were upper and lower rollers, both $60 \mathrm{~mm}$ in diameter and $15 \mathrm{~mm}$ thick. The upper roller was fixed by screws on the machine body. And a fixed holder was mounted on its lower side. The lower roller was made of hardened JIS SKS 95 (700 Hv) and was polished with 1000 grit emery paper. The testing specimen was bonded by quick setting glue to the fixed holder. During the measurement process, the lower roller was driven against the specimen by a servo-controlled d.c. motor, capable of variable rotating speeds. Loads 
TABLE 1

Surface Properties of the Specimen in this Study

\begin{tabular}{cccc}
\hline Specimen & Hardness & \multicolumn{2}{c}{ Roughness } \\
& $\left(\mathrm{H}_{v}\right)$ & $\left(\mathrm{R}_{a}\right)$ & $\left(\mathrm{R}_{\max }\right)$ \\
\hline Ti-25Al & 290 & 0.36 & 3.1 \\
Ti-40Al & 300 & 0.35 & 3.7 \\
Ti-50Al & 248 & 0.33 & 3.8 \\
Ti-53Al & 245 & 0.35 & 3.4 \\
\hline
\end{tabular}

were applied to the fixed holder through a load arm. Friction was monitored continuously throughout each test and friction force was measured using a load cell dynamometer. The total sliding distance for each specimen was $225 \mathrm{~m}$. The experimental data were collected graphically by using a chart recorder. After friction testing, the specimens were ultra-sonically cleaned in acetone to remove adhered debris and the resultant wear surfaces were examined by a Philips SEM 515 scanning electron microscope.

\section{$\underline{\text { Results }}$}

The values of the friction coefficient $\mu$ at various sliding speeds and applied loads for each of the four titanium aluminides are shown as a function of sliding distance in Figs. 2 and 3. From Figs. 2 and 3 it is clear that under the testing conditions the friction coefficients of Ti-53Al are the highest, while those of Ti-25Al are the lowest among four tested intermetallics. The friction curves of all specimens are characterised by an initial transient state, where the friction coefficient rapidly increases, followed by a steady state. The friction curve of Ti-25Al, however, has a slower initial increase and a lower friction coefficient than those of the higher aluminum content aluminides. In other words, longer time is needed before the initial material surface asperities contact for Ti-25Al. Typical surface morphologies of the specimens after testing are represented in Fig. 4. In all cases, a large amount of white powdery debris is produced during the testing of Ti-40Al, Ti-50Al and Ti-53Al, whereas only a small quantity is produced during the testing of Ti-25Al.

\section{$\underline{\text { Discussion }}$}

From the microscopic studies of Fig. 4, the dry sliding friction between titanium aluminide and the steel counterface can be related to the three factors, adhesion, ploughing and asperity deformation, generally

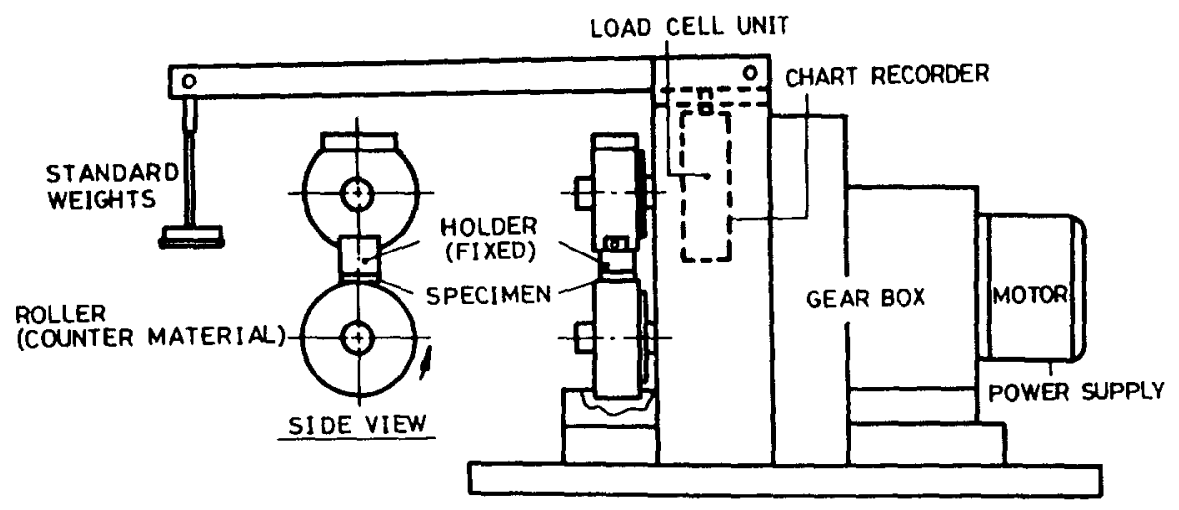

Figure 1. Schematic diagram showing the uni-directional sliding test configuration. 

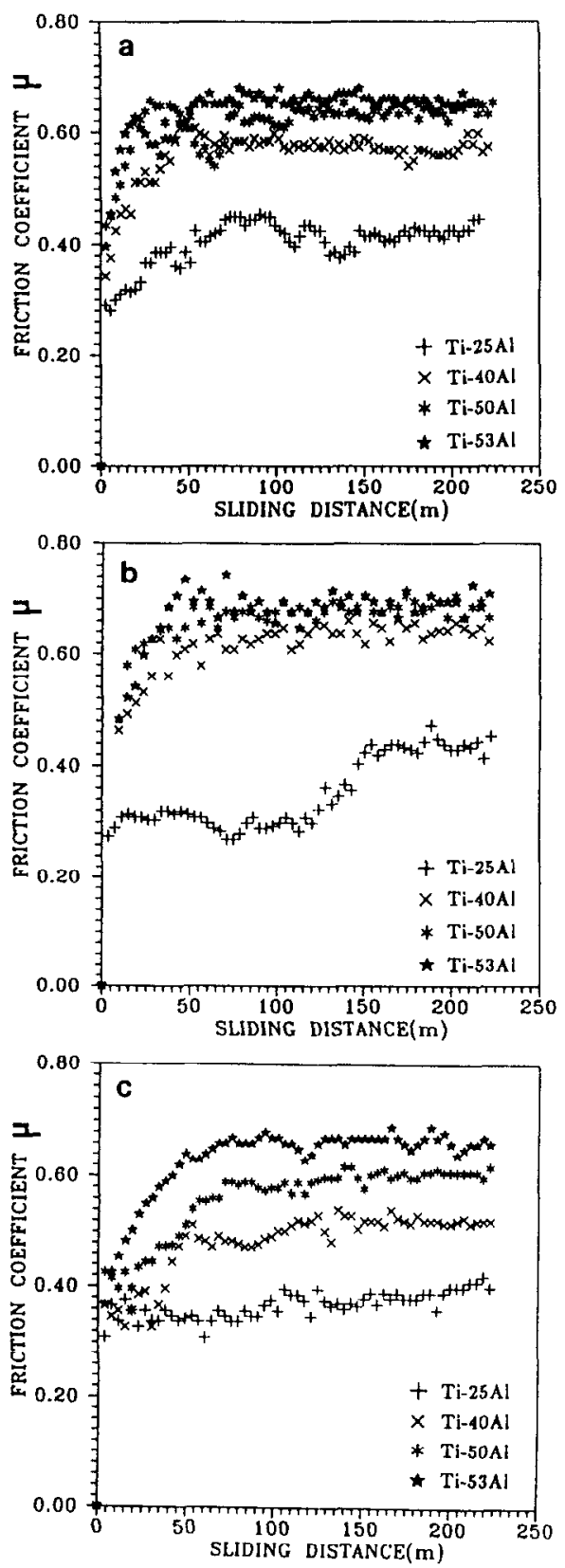

Figure 2. Friction coefficient $v s$. sliding distance at load $51.8 \mathrm{~N}$ and various sliding speeds (a) 0.236 $\mathrm{m} / \mathrm{s}(\mathrm{b}) 0.314 \mathrm{~m} / \mathrm{s}(\mathrm{c}) 0.628 \mathrm{~m} / \mathrm{s}$.
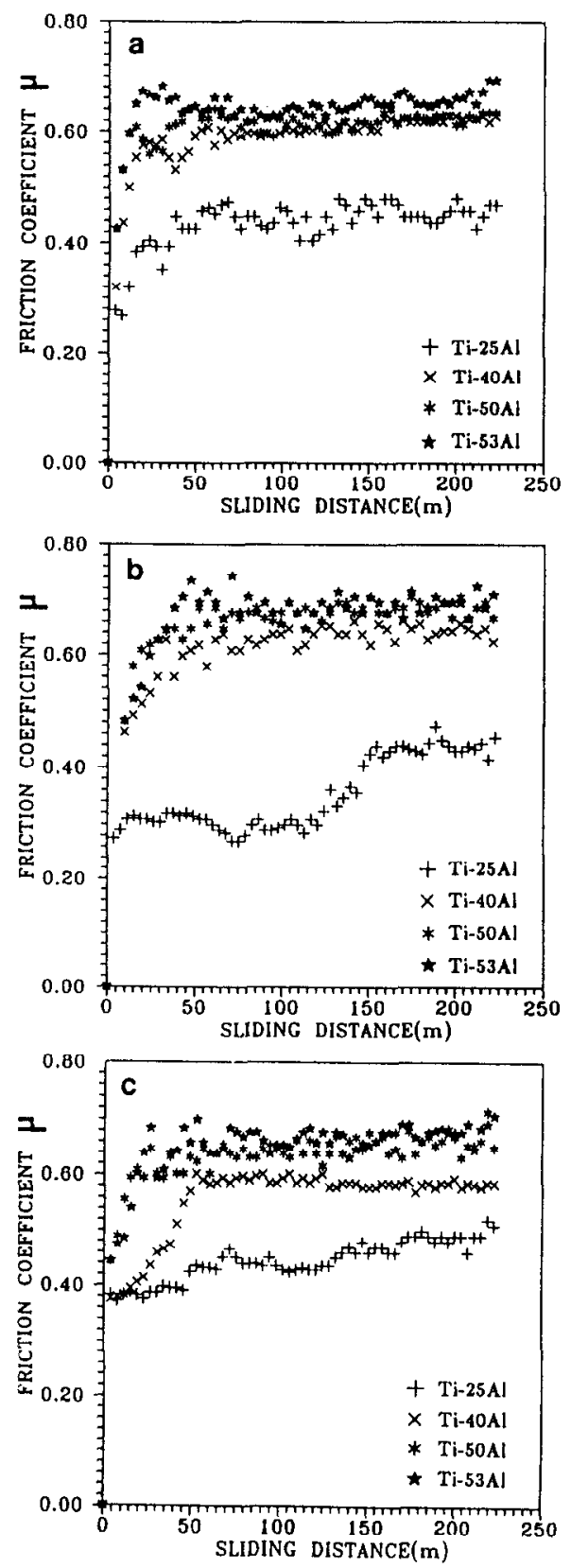

Figure 3. Friction coefficient vs. sliding distance at sliding speed $0.314 \mathrm{~m} / \mathrm{s}$ and various applied loads (a)46.9N(b)51.8N(c)66.5N. 


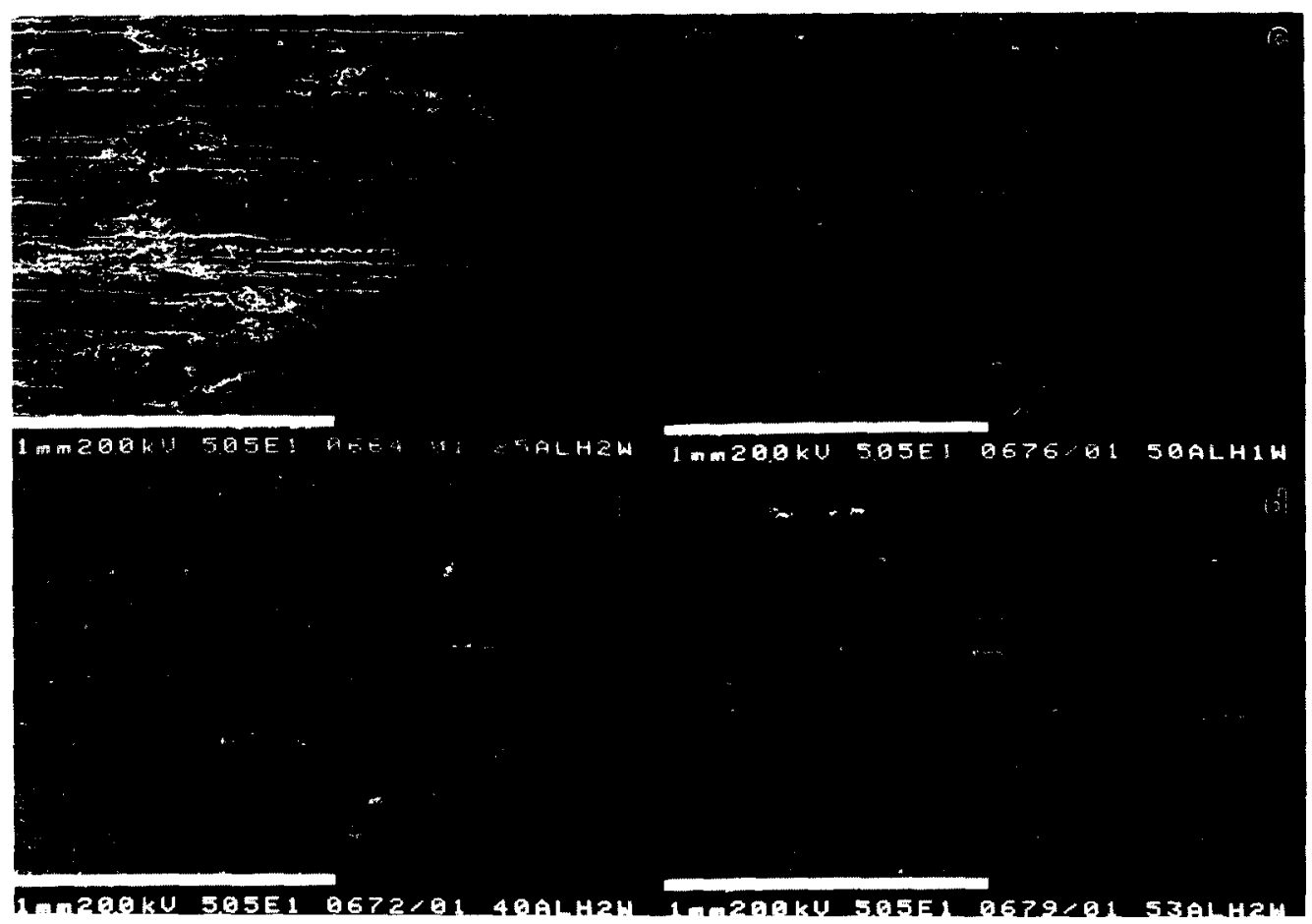

Figure 4. Scanning electron micrographs of the friction tracks produced on surface of (a)Ti-25Al(b)Ti-40Al(c)Ti-50Al(d)Ti$53 \mathrm{Al}$ after sliding distance of $350 \mathrm{~m}$, showing the ploughing grooves(load $51.8 \mathrm{~N}$; speed $0.314 \mathrm{~m} / \mathrm{s}$ ). Arrow indicates the sliding direction.

believed to cause friction [6]. Among these three factors ploughing is the most important. As shown in Table 1, all the investigated titanium aluminides are much softer than the steel counter-material. Therefore, deformation occurs mainly on the softer specimen surface. At the beginning of the sliding process, the softer specimen is ploughed by the hard asperities of the counter-material surface. Accordingly, ploughing plays the most important role in determining the initial friction coefficient of contacting pairs.

In addition to ploughing, adhesion contributes significantly to the friction results for Ti-25Al. For the higher aluminum content aluminides, instead of adhesion, asperity deformation is significant as evidenced by the large amount of white powdery debris is produced. In our previous study [7], Ti-25Al, Ti-40Al and Ti-53Al alloys consisted mainly of $\alpha_{2}$ single phase, $\alpha_{2}+\gamma$ laminar structure and $\gamma$ single phase, respectively. Ti-50Al was made up of predominantly $\gamma$ grains with some $\alpha_{2}+\gamma$ laminar structure. Since the ordered $\alpha_{2}$ structure has a higher ductility than the $\gamma$ phase [1], we believe that the asperity deformation in the higher aluminum content aluminides during the sliding process is due to the poor ductility of the $\gamma$ phase. The higher ductility of $\mathrm{Ti}-25 \mathrm{Al}$ [1] results a galling-like adhesive surface after the sliding test, as shown by arrows in Fig. 4(a).

In this study, the steady state friction coefficient exhibits a significant drop as the sliding speed is increased from $0.314 \mathrm{~m} / \mathrm{s}$ to $0.628 \mathrm{~m} / \mathrm{s}$, as shown in Fig. 2(b) and 2(c). It can be seen that, at higher speeds, contact shearing or ploughing is so rapid that heat is generated at a rate much faster than it can be conducted away. The intense localized heat alters the material properties of the surface layer and lowers the strength of the contact surfaces, thereby lowering the friction coefficient. In addition, increasing sliding speed also results in a longer initial transient stage or sliding distance before the steady state is reached. This is shown clearly by the Ti-25Al sample in Fig. 2 . Here the sliding distance of the initial transient stage is about $70 \mathrm{~m}$ for a sliding speed of $0.236 \mathrm{~m} / \mathrm{s}$. But this distance increases to about $150 \mathrm{~m}$ for $0.314 \mathrm{~m} / \mathrm{s}$ and to longer 
than $230 \mathrm{~m}$ for $0.628 \mathrm{~m} / \mathrm{s}$. The initial low $\mu$ shown in Figs. 2 and 3 is thought to be due to the low initial true contact area under the hertzian contact, which is incapable of providing a high shear resistance. Only when the contact area has increased due to the wear is Amonton's law obeyed and a truly representative friction coefficient value obtained.

The steady state friction coefficient for the four titanium aluminides is only slightly affected by the applied load in this study, as shown in Fig. 3. The effects of the applied load on the friction coefficient can be assessed from the real contact area of the rubbing surfaces and their deformation state. Normally, the friction coefficient would readily approach a stable value when the applied load is sufficiently high. However, the applied load used in this study may be not enough high. Therefore, the increasing applied load of Fig. 3 only results in a longer initial transient stage and a greater sliding distance before the steady state can be reached. This feature is more significant for Ti-25Al than for the other titanium aluminides. For example in Ti-25Al of Fig.3, the sliding distance of the initial transient stage is about $50 \mathrm{~m}$ for a $46.9 \mathrm{~N}$ applied load. This distance increases to about $150 \mathrm{~m}$ for $51.8 \mathrm{~N}$ and to over $230 \mathrm{~m}$ for $66.5 \mathrm{~N}$. This is because the $\alpha_{2}$ phase of Ti-25Al has higher hardness and ductility than $\gamma$ phase, as shown in Table 1 and Ref.[1].

\section{Summary}

The results of the dry uni-directional sliding test for titanium aluminides are characterised by an initial transient state followed by a steady state. Among the four tested titanium aluminides, Ti-53Al exhibits the highest stcady state friction cocfficient $\mu$ and Ti-25Al exhibits the lowest. In addition, incrcasing sliding speed results in a longer initial transient stage and a significant decrease in the friction coefficient. The increasing applied load only affects $\mu$ slightly. Ploughing is the major friction mechanism in this experiment. During the sliding process, titanium aluminides are ploughed by the hard asperities of the steel roller surface, forming many ploughing grooves on the sample face. In addition to ploughing, adhesion is a significant friction mechanism for Ti-25Al. For the higher aluminum content aluminides, ploughing and asperity deformation both are contributing mechanisms. The microstructures of $\alpha_{2}, \alpha_{2}+\gamma$ or $\gamma$ phases inherently formed in these titanium aluminides are closely related to the above wear mechanisms.

\section{$\underline{\text { References }}$}

1. Y. W. Kim, JOM, 46(7), 30(1994)

2. D. H. Buckley, Surface Effects in Adhesion, Friction, Wear, and Lubrication, p.353, (National Aeronautics and Space Administration, Lewis Research Center, Cleveland, OH), Elsevier, Amsterdam(1981).

3. M. Ignatiev, E. Kovalev, I. Melekhin, I. Yu. Smurov and S. Sturlese, Wear, 166, 233(1993).

4. A. Chen, K. Sridharan, J. R. Conrad and R. P. Fetherston, Surf. Coat. Technol., 50, 1(1991).

5. J. A. Hawk, D. E. Alman and N. S. Stoloff, Scripta Metall. Mater., 31, 473(1994).

6. Z. P. Huang, Y. Sun and T. Bell, Wear, 173, 13(1994).

7. C. L. Chu and S. K. Wu, submitted to Surface and Coatings Technology, (1994). 